\title{
Public Health Education in Central and Eastern Europe, and Central Asia
}

\author{
Róza Ádany MD, PhD, Dsc, ${ }^{1}$ \\ Anita Villerusa, $\mathrm{PhD},{ }^{2}$ \\ Jovanka Bislimovska, $\mathrm{MD}, \mathrm{PhD},{ }^{3}$ \\ Maksut Kulzhanov, MD, $\mathrm{PhD}^{4}$
}

\begin{abstract}
The relative risk of premature mortality of the population in Central and Eastern European (CEE) and Central Asian Republic (CAR) countries is more than twice as high (and up to four times higher for post-Soviet republics), as compared to the average of the 15 states that comprised the European Union before May 2004 (EU15). The difference in average life expectancy at birth between the EU15 and the CEE countries is more than seven years, and it reaches ten years in certain postSoviet states such as Kazakhstan, the Russian Federation, and Ukraine. ${ }^{1}$ This not only reflects the considerable public health problems in these countries but also seriously hampers sustainable development and international competitiveness of their economies due to weakening human and societal resources. Improving the health of the population in the CEE countries is a key challenge of our times and the pivotal role of schools of public health in the training and orientation of the necessary human resources is unequivocal. In this article, we explore various projects designed to raise the level of public health training and examine the education systems in six former socialist countries that have reorientated their training since the early 1990s. Sustained and expanded efforts to promote public health education and policy awareness in these countries is vital to bringing best international health standards to these countries, which are still transitioning away from the remaining dominance of the Soviet Semashko system and philosophy.
\end{abstract}

Key Words: Public health education, Central and Eastern Europe, Central Asian Republics

Recommended Citation: Adany R, Villerusa A, Bislimovska J, Kulzhanov M. Public Health Education in Central and Eastern Europe, and Central Asia. Public Health Reviews. 2011;33:105-33.

\footnotetext{
${ }^{1}$ Faculty of Public Health, University of Debrecen, Debrecen, Hungary.

${ }^{2}$ Faculty of Public Health, Riga Stradins University, Riga, Latvia.

${ }^{3}$ Center of Public Health, Medical Faculty, Ss. Cyril and Methodius University, Skopje, Macedonia.

${ }^{4}$ Kazakhstan School of Public Health, Almaty, Kazakhstan.
}

Corresponding Author Contact Information: Róza Ádany at adany@dote.hu; Faculty of Public Health, University of Debrecen, Debrecen, Hungary. 


\section{INTRODUCTION}

\section{Public Health Practice and Education in the Former Soviet Union and the Central and Eastern European Countries}

The history of public health practice and education in the Central and Eastern European (CEE) region is strongly linked to the Semashko model, originating shortly after the Russian revolution and spreading with the communist takeover in the CEE countries (especially in the former German Democratic Republic, the Czech Republic, Slovakia, Hungary and Poland, with certain elements also practiced in other states occupied or influenced by the Soviet Union). Nikolai Semashko became the People's Commissar of Public Health in 1918, serving in that role until 1930 in the former Soviet Union. From 1921 to 1949 Semashko was Chairman of Social Hygiene in the Medical Faculty of Moscow State University, and from 1940 to 1949, he was Chairman of the All-Union Hygiene Society. Under Semashko's leadership, in addition to the creation of the health care and insurance system, the foundations of Soviet public health were laid, with emphasis on work carried out to combat epidemics, and a system of protection for mothers and children.

The Soviet Union's health programme was administered in the "most democratic way" and, as with other institutions in the Soviet Union, its administration had the form of a "triangle with a very broad base". The base of this triangle was formed by the thousands upon thousands of committees, which existed in every factory, every farm, and every place of work. These committees cooperated with local doctors in order to give feedback and improve services; they ensured that the workers' social insurance funds were spent in the most appropriate way; they controlled the hygienic conditions of their place of work and the nurseries; and they organised health education in the workplace. Elected representatives from the workplace were involved in the next highest form of organisation - the Soviets. The Soviets were responsible for the supervision of all hospitals and sanitary establishments, sanitary inspections, and wider organisation of education in personal and community hygiene.

The next tier of organisation was the district (i.e., "rayon"), of which there were around 3,000 in the USSR. In each district there was a Health Department, headed by a Rayon Inspector of Public Health, who was responsible for the entire health work of the district, and who controlled, inspected and advised all medical institutions. At the apex of the pyramid stood the Commissariat of Health, which was advised by the various scientific research institutions. 
Traditionally, in the Soviet Union, training in the field of "hygiene" was organized within certain medical universities, mainly in Moscow and Saint Petersburg (formerly Leningrad), on a track parallel to but clearly separated from those for training of medical practitioners. The medical universities were not part of multi-faculty universities and were under the direct supervision of the Ministry of Health.

The Leningrad Medical Institute of Hygiene and Sanitation was created by the reorganization of the Leningrad Medical Institute in 1947, and operated under this name until 1994 when the Institute was renamed the Saint-Petersburg State Mechnikov Medical Academy. In Moscow, the Institute of Social Hygiene, which was organized in 1919, was the first scientific research centre of hygiene and in 1926 the sub-department of the school of hygiene was established at the medical department of the First Moscow State University. Community hygiene became an independent discipline in 1933, when a sub-department of community hygiene was created at the First Moscow Medical Institute.

Hygiene doctors were employed by the Sanitary Epidemiological (Sanepid) system of the State Epidemiology Service, which was responsible for the surveillance of infectious diseases and sanitary issues (e.g., food and water safety, immunization, hygiene of school children, environmental and occupational safety, and many other fields of public health practice). Hygienists in the Eastern Bloc countries were trained at the institutions in Moscow and Leningrad and therefore, the corresponding conceptual approaches dominated the public health services in these CEE countries. The last cohort of hygienists trained in this manner graduated in the 1990s. They continue to have significant influence on the public health servicesunfortunately mainly by inhibiting the implementation of modern public health approaches-even today.

However, in some former Eastern Bloc countries, medical faculties retained a more international and solid basis for initiation and development of public health education. Public health practice and education in the former Yugoslavia as a whole was inextricably linked to Andrija Stampar (1888-1958) and the internationally recognized "Andrija Stampar" School of Public Health of Zagreb. This pioneering school was founded in 1926 as a part of the Institute of Hygiene, upon the initiative of a group of public health workers led by Dr Andrija Stampar and with financial support from the Rockefeller Foundation. It became an independent institution in 1947 and was the source of education for a large number of public health professionals. A network of public health institutions gradually emerged in the country starting with the Institute of Hygiene, later transformed into the 
Republic Institute for Health Protection. Additional regional institutes for health protection and their branch units were located throughout the country, developing services for maternal and child health, immunization, occupational health and other areas. The formal public health education taught at the Faculty of Medicine within the Departments of Hygiene, Social Medicine, Occupational Health, Microbiology and Epidemiology was more closely linked to clinical medicine and medical education based on western ideas than to the Soviet model and philosophy.

\section{CHANGES IN THE FIELD AFTER 1990}

As discussed above, prior to 1990, public health services in the CEE countries were mostly organized following the Soviet model with a high priority on carrying out regulatory hygienic and sanitary control measures to combat infectious diseases. In consequence, public health educational institutions/departments developed and taught programmes with a high priority on monitoring and controlling communicable diseases.

Since 1990, the concept of a "New Public Health" as a contemporary application of a broad range of evidence-based scientific, technological, and management systems implementing measures to improve the health of individuals and populations became more and more widely accepted in the CEE countries..$^{2-4}$ This new approach, which took into account the crucial importance of chronic non-communicable diseases, as well as that of health policy, health promotion, health systems management issues, and public health practice, became increasingly recognized leading to the reformulation of educational programmes.

Public health began to take a broader view than it had previously, aimed at improvement of health, prolongation of life and improvement of the quality of life in populations by using a multidisciplinary theoretical approach which should be translated into effective intersectoral practice. ${ }^{5}$ Only highly trained professionals can implement these elements of effective public health. In the former socialistic countries the lack of well-trained professionals (and in general the low-level of professionalisation of public health) was, and still remains, a general problem. Specialists who have completed their studies in the newly evolving context of schools of public health are exposed to and will have acquired a thorough training in modern epidemiology, health promotion, health care management, and health policy. 


\section{The Support of ASPHER to Reform Public Health Training in the CEE Countries}

The Association of Schools of Public Health in the European Region (ASPHER) ran three projects of particular importance in the development of schools of public health in the CEE region. These projects provided an excellent framework for developmental activities in the CEE schools.

1. On the basis of ASPHER's international Public Health Education European Review (PEER) experiences, a collaborative project was initiated to develop a guideline proposal for the accreditation of training programmes, as well as to initiate the development of a transnational accreditation body for public health education programmes in the European Region. ${ }^{6}$

2. ASPHER, in partnership with the Open Society Institute (OSI) of New York, initiated a joint project that was aimed at developing quality in public health training programs, within educational entities particularly throughout the CEE region. "Strengthening and deepening public health education and training and "building public health education and training capacity were the goals targeted in the development of CEE schools and the partnership between the CEE schools and members of the ASPHER network. The duration of programme implementation was three years, spanning the academic years of 2001/2002, 2002/2003 and 2003/2004. The OSI-ASPHER projects were documented by Goodman, Overall and Tulchinsky in a 2008 publication available from ASPHER's website*. ${ }^{75}$

3. A European Training Network was created in which the member schools are eligible to offer the European Master in Public Health (EMPH) degree, certifying the acquisition of a "European" competence. ${ }^{8}$

\section{Projects to Improve Public Health Practice in the CEE Countries}

As has been published previously, ${ }^{9}$ in the past two decades a number of national health promotion programs were initiated by other major international funding agencies in the CEE countries that focussed on projects aimed at reforming the health sectors. Regrettably, in spite of the fact that these health promotion programs were generously financed and running for several years, very little, if any information is available on their planning, implementation and evaluation in the English language public health literature.

* URL: www.aspher.org (Accessed 9 September, 2011). 
The development of schools of public health was strongly facilitated by a number of internationally funded health reform projects which were implemented around the turn of the millennium, including:

1. Albania - Kosovo: The American International Health Alliance in conjunction with the United States Agency for International Development (USAID) launched a community-based primary health care partnership with the Primary Care Directorate of the Lezha District in 2001 in Albania; an element of the partnership is the creation of a community education and health promotion programme.

2. Czech Republic: The Partners in Health Program was launched at the initiative of the Center for Communications, Health and the Environment (CECHE) in 1992. The programme had a community-oriented and a high risk-oriented component, and used nutrition intervention, smoking prevention and cessation activities, stress control, and the promotion of physical activity to reduce cardiovascular morbidity and mortality. ${ }^{10}$

3. Croatia: A Health System Project supported by the World Bank was launched in 1999, which included a national health promotion strategy, development and training. ${ }^{11}$

4. Hungary: A Health Services and Management Project financed in part by the World Bank had been in effect during the period from 1993 to 2000. One subcomponent of the project was planned and implemented as a community-based comprehensive health promoting programme including approaches of health status monitoring, school health, nutrition, communication and education, physical activity, and screening for major non-communicable diseases. Within the framework of this programme, the National School of Public Health at the University of Debrecen was established. In 2001, the Hungarian Government accepted and launched a national health promotion programme, For a Healthy Nation - Public Health Programme 2001-2010, ${ }^{12}$ which was followed by the National Public Health Programme for the Decade of Health in 2003. ${ }^{13}$

5. Romania: A Health Sector Rehabilitation Project had been running during the period 1991-1999, which included a health promotion programme.

6. USAID financed programmes on maternal and child health promotion (Romania), and HIV control and prevention (Romania, Albania).

7. Countries of the CEE region participated in several health-promoting networks of the World Health Organization such as the Countrywide Integrated Noncommunicable Diseases Intervention (CINDI) programme and Healthy City, Healthy School programmes have been running in Albania, Bulgaria, Croatia, Czech Republic, Hungary, Poland, Romania, Slovakia, Slovenia, Macedonia and Yugoslavia. ${ }^{14}$ 


\section{EXAMPLES OF THE DEVELOPMENT OF SCHOOLS OF PUBLIC HEALTH IN THE CEE COUNTRIES}

\section{Newly Independent States (NIS)}

In the Baltic countries, since 1991, the traditional public health teaching in the field of medical education with an emphasis on hygiene and infection control has gradually been replaced with training in modern public health. The transition from Soviet-style Departments of Social Medicine and Hygiene to Departments of Public Health meeting international standards required the development of human resources more than that of physical facilities. Teaching staff needed specific training in new public health, epidemiology, health promotion, health economics, management and health care evaluation, etc.

The Nordic countries have been assisting the Baltic countries in their public health development since the early nineties. Significant support was provided by the international project Baltic Rim Partnership for Public Health (BRIMHEALTH). The main objective of the project was to ensure the proper development of the public health functions in the countries through support for national strategies for public health development and training programmes for public health professionals. ${ }^{15,16}$ The courses of the BRIMHEALTH programme were incorporated into the curricula of a number of public health training institutions in Estonia, Latvia, and Lithuania and also in St. Petersburg. ${ }^{17-19}$

\section{Latvia}

In Riga Stradins University, the Department of Public Health and Epidemiology was established in 1992, employing the staff of the former Department of Social Medicine. A training programme in public health and epidemiology was first developed for medical students, followed up some years later by programmes for the students of the Faculties of Pharmacy, Rehabilitation and Nursing. As a result, all students who have successfully finished studies in medical and health sciences have at least some insight into the concept of public health.

The second stage was the development of public health education in Latvia. In 1994, a postgraduate public health training was developed in the newly established School of Public Health which was independent from the main university. In 1996, the School of Public Health launched a Master of Public Health (MPH) (accredited by the Ministry of Education and Sciences of the Republic of Latvia for the period of 2000-2002). Most of the students 
who enrolled in this programme had a medical background and were senior managers in various health care institutions.

In 1997, the Faculty of Public Health was established at Riga Stradins University and a Bachelor Programme in Public Health was developed. The mission of the bachelor's programme was to supply the state of Latvia with well-trained public health specialists equipped with a broad spectrum of knowledge in fields such as environmental health, occupational health, food safety, disease surveillance, health promotion, health policy and management.

In 2000, the Faculty of Public Health introduced a Master of Science in Public Health (MScPH), which was further improved in partnership with the OSI-ASPHER developmental project. Each year, approximately 24 bachelor's and ten master's level students are accepted into the programmes and financed by the state. At present, 16 departments of Riga Stradins University are involved in the public health bachelor's and master's courses. The main organizing department is the Department of Public Health and Epidemiology with eight staff members.

Riga Stradins University also has doctoral level training with specializations in public health and epidemiology. Presently, 12 doctoral students are in the department and many of them participate in the bachelor's and master's programmes. Specialists from public health practice are also involved in teaching and this collaboration is believed to have increased stakeholder awareness of the programmes and has promoted better recognition of the graduates. Since its establishment, 159 students in the bachelor's training programme and 68 students in the master's programme have graduated in Latvia. ${ }^{20}$

\section{Estonia}

The Department of Hygiene at the University of Tartu was first established in 1895. During the Soviet era (1940-1991), public health services were provided via Sanepid stations, later named Health Protection Services. The staff working in the field of public health in Estonia received a four- or fiveyear training at specialised institutions, called Institutes or Faculties of Sanitary Epidemiology either in St. Petersburg, Moscow or elsewhere outside of Estonia. Thus, no professional public health training was carried out in Estonia during this time period and the teaching and training activities of the Department of Hygiene were aimed at and limited to teaching of public health disciplines to the undergraduate students in medicine, dentistry and pharmacy.

After Estonia regained its independence in 1991, the Department of Hygiene at the University of Tartu was reorganised into the Department of 
Public Health. The importance of preventive medicine, including a population-based approach, was recognised. The proportion of public health subjects was doubled in the curriculum for medical students. At the same time, the number of staff in the Department of Public Health doubled as well. Further changes were brought about in 1996 at the time when Professor Astrid Saava headed the Department. Within the framework of the Estonian Health Project financed by the World Bank, new Chairs of Health Promotion, Epidemiology and Biostatistics, and Health Economics were established adding to the existing Chairs of Health Care Management and Environmental and Occupational Health. The Department also set about improving the qualifications of its staff by employing better-trained workers and enabling a number of its staff members ( 7 persons) to complete their MPH abroad.

Throughout the 1990s, discussions on establishing training for health professionals in preventive and/or public health medicine were ongoing, supported by the World Bank's Estonian Health Project. The curricula of $\mathrm{MScPH}$ and MPH programmes were developed with close cooperation between both academics and professionals from 1998 to 2000. The first group of ten MPH students enrolled in September 2000 and graduated in 2002. This was the first time in history that public health specialists were trained in Estonia and by 2008, 70 MPH students had graduated from these programmes.

The continuing mission of the Department of Public Health at the University of Tartu is to improve health and prevent disease in Estonian populations by acquiring, disseminating and applying public health knowledge. This mission is realized by following a set of objectives: to train and teach future professionals in public health through master's and doctoral programmes and residency training;

- to contribute to training of medical professions;

- to conduct basic and applied research for identification, analysis of and intervention for health-related problems among Estonian populations;

- to achieve a balance between teaching and research;

- to provide service and consultancy in public health;

- to encourage multidisciplinary and interdisciplinary approach;

- to develop strong external relationships with public health practitioners and programmes in the community;

- to strive for international co-operation in training and research. ${ }^{21}$

The programme offers specializations in Health Care Management, Health Promotion, Environmental Health and Epidemiology. Admission to the master's programme is possible for graduates of medicine, social 
sciences, mathematics/mathematical statistics and economics. The degree awarded is Master of Sciences in Health Sciences (Public Health). During the last ten years, the master's programme has further developed following the recommendations of the international PEER review board of ASPHER. The programme received full accreditation in 2009 from the Estonian Higher Education Quality Agency, which remains valid until 2016.

Over the last three years, the development of a module in epidemiology has been supported by a grant from the Norwegian Financial Mechanism in order to create a critical mass of specialists in epidemiology who can collect and analyse public health data and support evidence-based health policy in the country. As of the year 2010, the programme had graduated 82 students with some of them entering into the University's doctoral programme.

\section{Lithuania}

In Lithuania, preparation of public health training programmes began in 1994. This complied with the demands of the public health reforms that were anticipated in the National Health Concept of Lithuania approved in 1991 by the Supreme Council - the Restoration Seimas of the Republic of Lithuania. The National Health Concept of Lithuania emphasized that more attention should be focused on health promotion and disease prevention.

Three universities in Lithuania offer public health training. In Kaunas at the Faculty of Public Health, Lithuanian University of Health Sciences (previously Kaunas Medical University) bachelor's, master's and doctoral level studies are available. In the capital city, Vilnius, there are also bachelor's, master's and doctoral courses offered at the Institute of Public Health of the Faculty of Medicine, Vilnius University. In Klaipeda, at the Department of Public Health of the Faculty of Health Sciences, Klaipeda University, only bachelor's level training is available.

The Lithuanian University of Health Sciences is the largest institution of medical education and training in Lithuania. Its history goes back to 1922, when the Faculty of Medicine was first established. The Faculty of Public Health was founded in 1994, offering a four-year Bachelor's Programme in Public Health. In 1997, the Faculty began a two-year Master in Management of Public Health (MPHM) programme and in 1998, a twoyear MPH programme. The Faculty also offers a PhD degree in Public Health. All study programmes are accredited according to the Lithuanian Higher Education Law. 
The mission of the School is to contribute to health improvement in the population by:

- providing high-level training in public health, developing professional skills and competencies;

- stimulating public health research;

- actively participating in health strategy development, policy implementation and evaluation;

- engaging with other organizations with a view to education, planning and research in public health or health management to respond to society's needs. ${ }^{22}$

The number of students accepted to the bachelor's programme is approximately 40 per academic year. The majority of graduates continue their studies in the master's programmes offered at the University of Kaunas. The number of entrants in the MPH varies yearly between 19 and 35. In 2003 ASPHER's PEER review was performed, focussing on the MPHM programme. The recommendations were taken into account for further improvement of the study programmes. ${ }^{23}$

The Department of Hygiene of the Faculty of Medicine of the Vilnius University was founded in 1922. During the Soviet period (since 1962) the Faculty of Medicine trained medical specialists in hygiene (i.e., preventive medicine). In 1994, after the independence of Lithuania a new study programme was prepared and in 1998 the title of "Hygiene" was replaced with "Public Health". This four-year bachelor's programme (240 ECTS*) was developed to incorporate all the major areas of public health. Following the external evaluation of the public health undergraduate study programme in 2003 significant changes were made to harmonize the programme with the needs of the new public health and international guidelines. Every year approximately 30 students are admitted into the programme. A MPH programme was started in 2005.

Klaipeda University was founded in 1991, the year when Lithuania declared its independence. The Faculty of Health Science and the Department of Public Health were established in 1999, following the economic and social reform of the country and focussed more attention on creating healthy environments. In the Bachelor of Public Health programme curriculum a special focus on primary health care, especially on preventive services at the primary health care level, was emphasized. In this regard, the BSc in Public Health curriculum profile is unique to Klaipeda and

\footnotetext{
* European Credit Transfer and Accumulation System.
} 
differs from the curricula at other universities. The aim of the undergraduate study programme in public health is to provide the knowledge and skills necessary for the assessment of population needs, for the formation of appropriate public health strategies, to design and implement programmes and projects, and to ensure the promotion of healthy lifestyles in the community. Approximately 20 to 25 students are enrolled each year in the bachelor's programme.

\section{Kazakhstan}

Kazakhstan inherited the Soviet system of training and retraining of health professionals and there have been few changes in this area in the years since independence, although it should be noted that there has been significant postgraduate training in family medicine and priority programmes including those concerning mother and child health and tuberculosis.

In Kazakhstan, public health functions are performed by different agencies, including the sanepid service (SES), HIV/AIDS centres, the National Centre for Healthy Lifestyles, primary health care providers, nongovernmental organizations, and international agencies. The biggest challenge of the country's health sector in the domain of public health lies in clarifying, coordinating and streamlining the roles and responsibilities of different agencies responsible for public health and health promotion activities. $^{24}$

In 1996, an MPH-like programme was developed, with assistance from ASPHER experts. The idea of the Kazakhstan School of Public Health (KSPH) was initially born out of a collaboration between the WHO Regional Office for Europe and the Kazakhstan Ministry of Health. Founded in 1997, it is an autonomous public health institution that provides postgraduate education in public health and health administration. KSPH is one of the first organizations of this kind amongst the NIS and the only one in the Central Asian Republics (CAR).

The primary mission of KSPH is to improve the nation's health through the development of public health. The school fulfils its mission providing accessible, student-focussed education, research and expert-consulting activities. KSPH provides long-term and short-term programmes targeted to train both health professionals and specialists in related fields working in the health sector.

$\mathrm{KSPH}$ is a member of key international health academic networks such as ASPHER, the Asia-Pacific Academic Consortium for Public Health (APACPH) and the Organization for PhD Education in Biomedicine and Health Sciences in the European System (ORPHEUS). Expertise in health 
care administration and research possessed by faculty members allow them to consult in such international organizations as WHO, USAID, and the World Bank; as well as to coordinate programmes and projects implemented under the auspices of WHO, USAID, OSI and other European and US institutions. KSPH also recruits young specialists who are attracted by the opportunity to work side by side with more experienced peers. KSPH programmes passed national accreditation in 2007.

The School regularly hosts international workshops, national and international conferences and meetings on relevant public health issues. KSPH publishes its own edition of the Journal of Central Asian Health Service Research, which has its own website and can be accessed electronically. ${ }^{25}$ Graduates of the MPH programme can execute different types of professional activity:

- pedagogic (instructors/trainers in middle professional and higher educational organizations);

- research (research officers in institutes, research centers);

- administrative-managerial (specialists in administrative bodies, consultants);

- expert consulting (experts, consultants in academic institutions).

A list of short-term courses is available at the school website*. ${ }^{26}$

Students at KSPH include administrative workers from the Ministry of Health and the Departments of Health from all over Kazakhstan, leaders of health care organizations, and researchers and employees of pharmaceutical companies. Since 1998, 143 students have graduated from the KSPH master's degree programme, along with 80 graduates of the Certificate Programme in Health Administration, and 15,292 people were trained in short-term programs. ${ }^{7}$

\section{The Former Yugoslavia}

\section{Macedonia}

The Republic of Macedonia achieved complete independence from Yugoslavia in September 1991. The health system inherited many characteristics from the former political system that posed significant challenges in transition. These challenges included the need to rationalize the provider structures, to reduce the oversupply of personnel in the health sector and to secure sustainable health financing, including adequate

* URL: www.ksph.kz (Accessed 9 September, 2011). 
funding for preventive programmes and capital investments. The World Bank supported a Health Sector Transition Project from 1996 to 2001 with a basic health services component aimed at the strengthening of primary health care and high-priority disease prevention and health promotion programs. Reforms in the health care sector have addressed the issues at all health care levels, including primary, secondary and tertiary levels. The strategic objectives, based on health policy formation, are clearly aimed to:

- improve the health status of the population in Macedonia;

- improve the quality of health care services;

- establish a sustainable, efficient and accessible health care system to all citizens; and

- establish a health care system that will adequately respond to challenges of globalization and harmonization of national health legislation with European Union health legislation. ${ }^{27}$

In the field of education, the Faculty of Medicine within the St. Cyril and Methodius University, Skopje has continued a long tradition of quality European-oriented medical education by creating well-educated and qualified professionals. The preventive medicine/public health field has been taught by the following departments: Epidemiology, Occupational Medicine, Hygiene and Social Medicine. The curricula of these preventive branches of medicine are mostly oriented towards the medical aspects of disease prevention and protection and promotion of the health status of the Macedonian population. There was a clear demand to address innovative modalities of teaching public health, not only to graduated medical students, but also to other professionals working or hoping to launch a career in public health. ${ }^{28}$

During the period 2001-2003, the initiative to establish a new centre as a basis for a School of Public Health was supported by the OSI. A memorandum of understanding on the development of a school of public health was signed between the OSI and the Faculty of Medicine and included a revision of the Medical Faculty's statutes, establishing the Centre of Public Health (CPH) with a Public Health Board and a Steering Committee for the development of the School of Public Health within the Medical Faculty in Skopje.

The CPH - by the decision of the Medical Faculty's Scientific Council (2003) — is an entity within the Medical Faculty, relying on existing human resources and infrastructure integrated into a consortium of preventive departments or divisions from within the Medical Faculty: Epidemiology and Biostatistics, Social Medicine, Hygiene, Occupational Health and Microbiology. The mission statement of the $\mathrm{CPH}$ supports the strategic aims: 
- to prepare a critical mass of public health professionals who are competent in the public health core content and methodological approaches for public health problem solving;

- to facilitate teaching, research, and provide public health services and analysis/formulation of national health policy.

Activities under the umbrella of $\mathrm{CPH}$ resulted in the preparation of a core curriculum for the MPH Programme; developed in line with ASPHER's internationally recognized standards and Macedonian legislation on higher education and guided by a team of consultants from the Braun School of Public Health, Hebrew-Hadassah University in Jerusalem. In addition, The New Public Health: An Introduction for the $21^{\text {st }}$ Century textbook was translated into and published in Macedonian, serving as a reference text throughout the MPH studies.

The MPH programme was launched in December of 2003 and since then, there have been approximately 25 students enrolled annually. In 2005, preliminary evaluation of the MPH programme emphasized the success of the programme, the great enthusiasm and satisfaction of both teachers and students and the recommendation to continue with the process of creating the School of Public Health. ${ }^{29}$ In 2010, the CPH Medical Faculty - Skopje launched a revised two-year master's programme, an $\mathrm{MScPH}$ programme and a new, three-year $\mathrm{PhD}$ in Public Health programme. In January of 2011, based on the decision of the National Accreditation Board, both the master's and doctoral studies were officially accredited. They will start in the new academic year 2011/2012.

\section{Hungary}

The first university department in the field of hygiene in Hungary was established by Jozsef Fodor at the Medical Faculty in Budapest in 1874. The Hungarian National Institute of Hygiene was subsequently founded in 1925 with the financial support of the Rockefeller Foundation and a health education network was established in 1926 based on the Decree of the Minister of Public Welfare and Labour. During the last 85 years, the names and organizational structure of the Institute were changed many times. Departments of Hygiene were created in the country's medical schools as early as the 1920s. These departments were involved almost exclusively in the training of medical doctors in sanitation and control of communicable diseases, while few departments of social medicine-created mainly after World War II in the era of "building socialism"- delivered courses on health care organization and management. 
Within the framework of the Health Services and Management Program of the Hungarian Government, and with the aid of a World Bank loan (1993-2000), the project of establishing a School of Public Health at the University of Debrecen began in 1996, serving as a foundation for the development of the first Faculty of Public Health in Hungary. The Faculty status was obtained by the decision of the Hungarian Government on the first of December, 2005, upon the unification of the School of Public Health, the Department of Preventive Medicine, the Department of Family Medicine and the Department of Behavioural Sciences of the University of Debrecen. ${ }^{30}$

Formation of the independent Faculty of Public Health at the University of Debrecen-presently uniting 15 different faculties-was preceded by a ten-year period of development. Between 1997 and 2005, establishment and launching of five different postgraduate and one graduate training programme as well as the establishment of a doctoral programme was carried out by the teaching staff with the effective support of the University of Debrecen and its Medical and Health Science Centre. As a result of these efforts, the Faculty became a unique, internationally recognised and competitive training centre in Hungary.

In 2007, in accordance with the Bologna process, the Faculty established and launched its bachelor's and master's training programmes in the field of public health and health sciences. With its two bachelor's (BSc in Public Health, BSc in Physiotherapy), four master's training programmes (MScPH with four specialities: public health officer, epidemiology, environmental and occupational health, health promotion; MSc in Health Psychology; MSc in Health Policy, Planning and Financing; and MSc in Complex Rehabilitation) and six postgraduate courses (Public Health, Environmental Health, Health Promotion, Epidemiology, Health Care Quality Assessment and Improvement, Hospital Hygiene and Infection Control), the Faculty of Public Health offers a rich variety of learning experiences. There are also two doctoral programmes available since 2002 and 2009. ${ }^{31}$

The mission of the Faculty of Public Health of the University of Debrecen as the centre of public health education in Hungary is to improve the health of the population by developing and maintaining internationally recognised high quality training programmes, complying with the training needs of public health and health care institutions, both at the graduate and postgraduate levels; pursuing excellence in research; and providing consultancy services. The Faculty of Public Health organises and carries out its training activities according to the professional guidelines of ASPHER. 


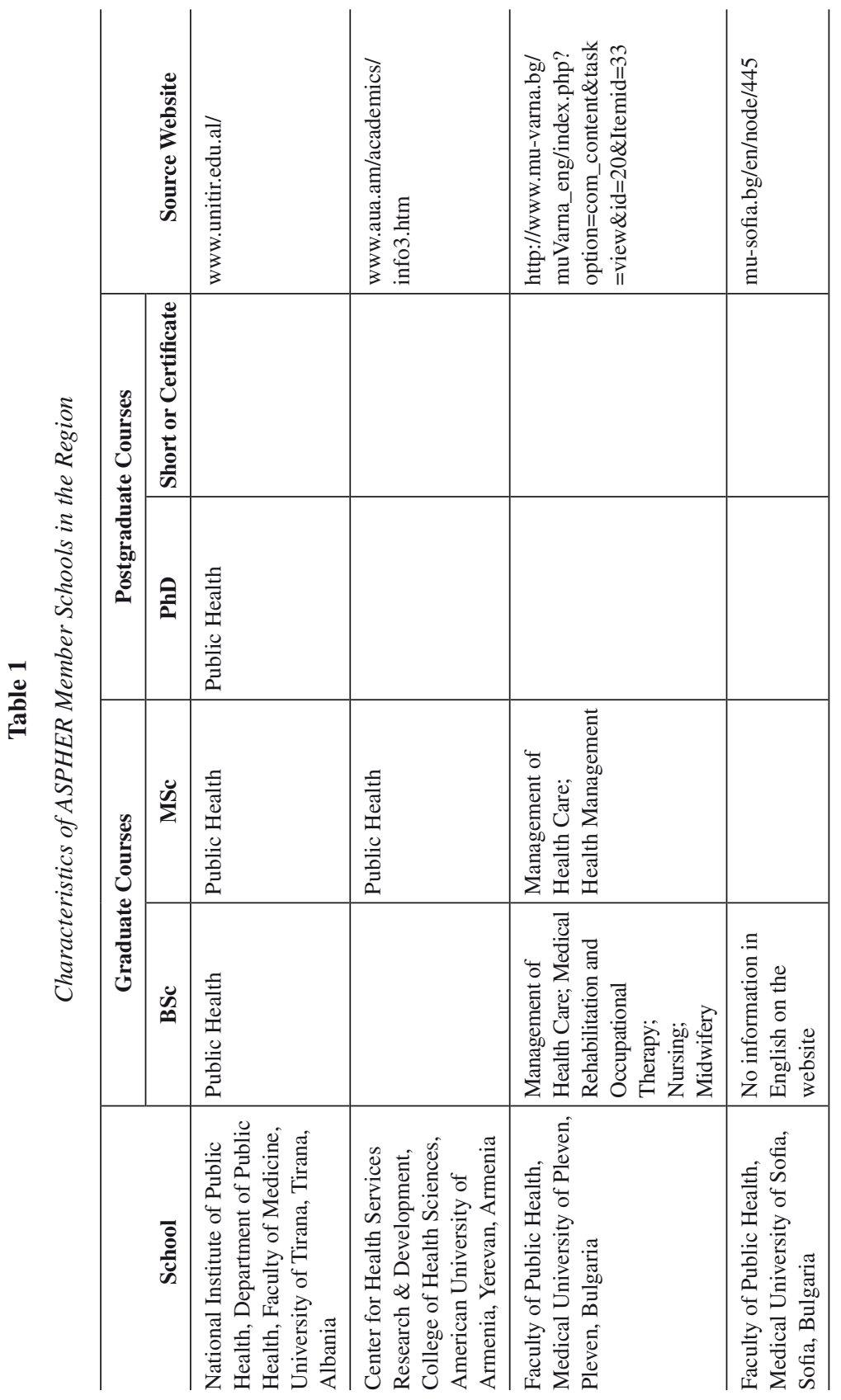




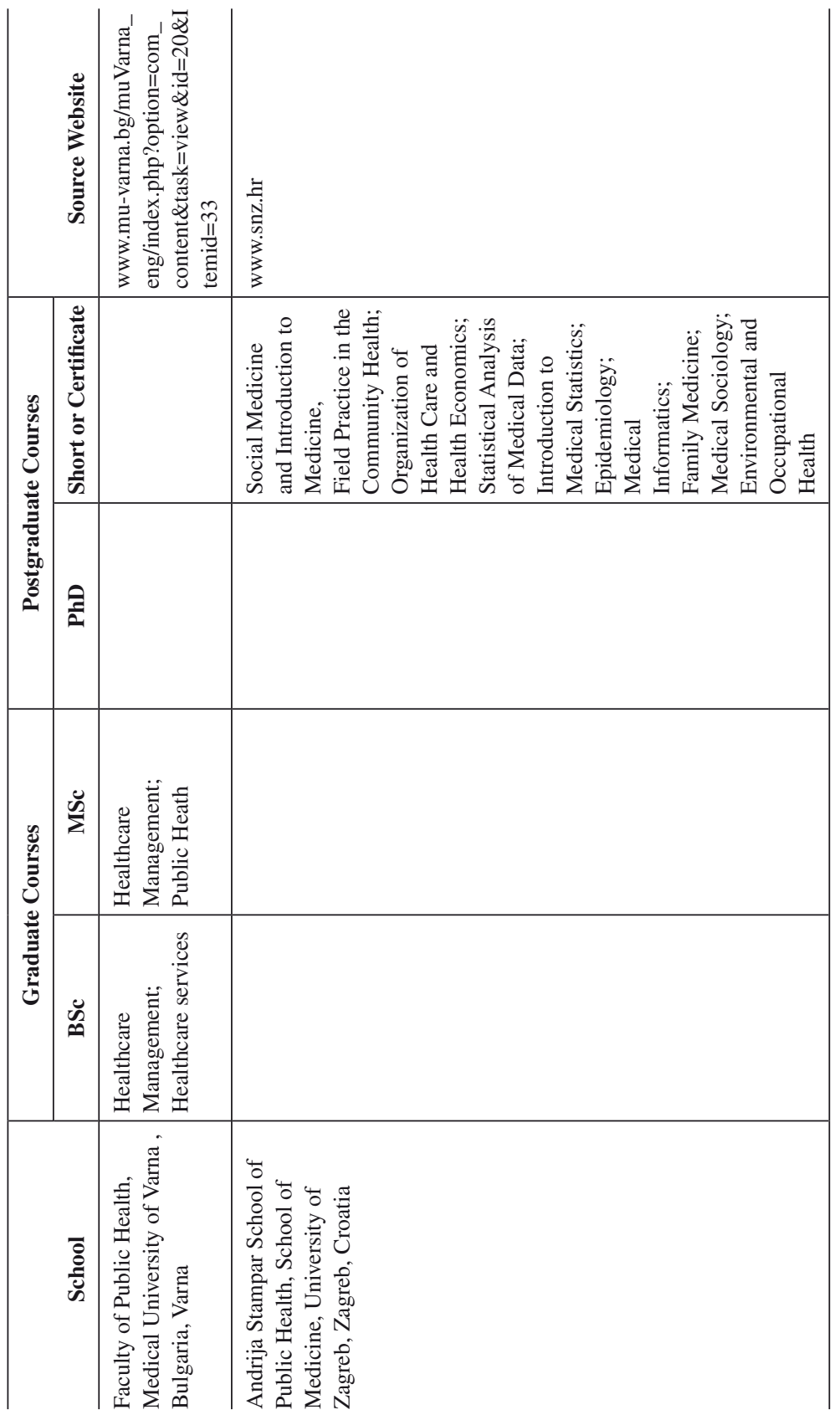




\begin{tabular}{|c|c|c|c|c|}
\hline & 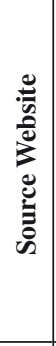 & 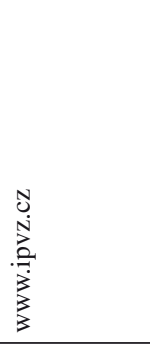 & 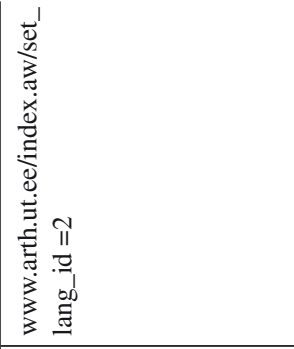 & 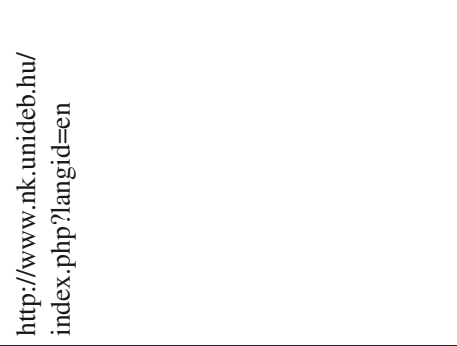 \\
\hline 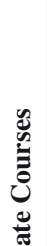 & 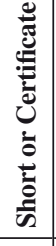 & & 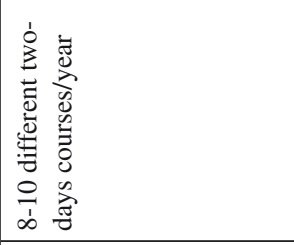 & 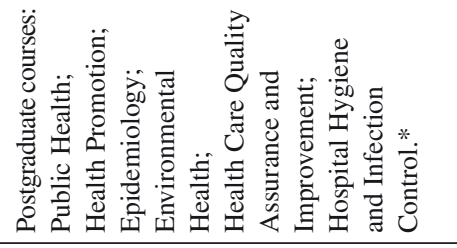 \\
\hline 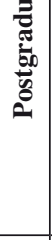 & $\stackrel{\text { I }}{\underline{\underline{a}}}$ & & 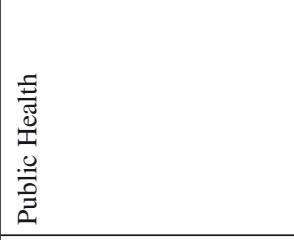 & 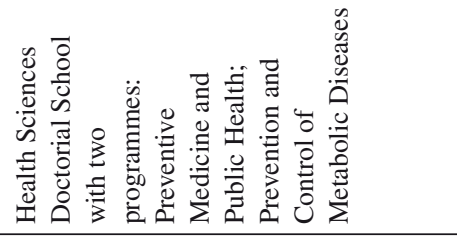 \\
\hline 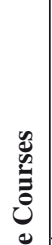 & 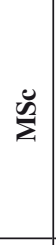 & & 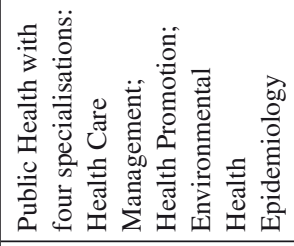 & 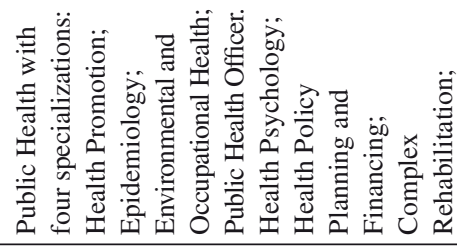 \\
\hline & $\ddot{\mathscr{n}}$ & 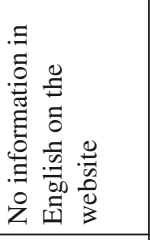 & & 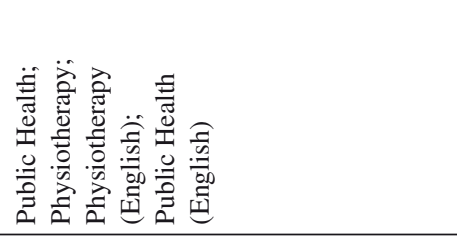 \\
\hline & 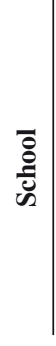 & 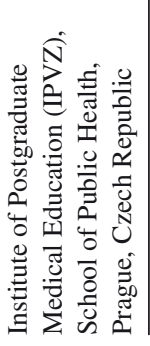 & 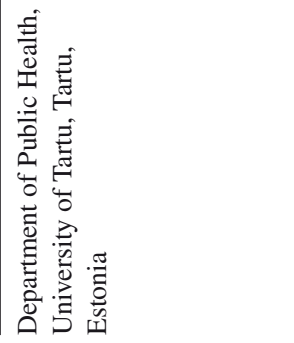 & 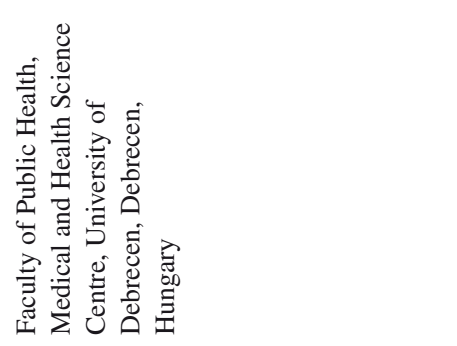 \\
\hline
\end{tabular}




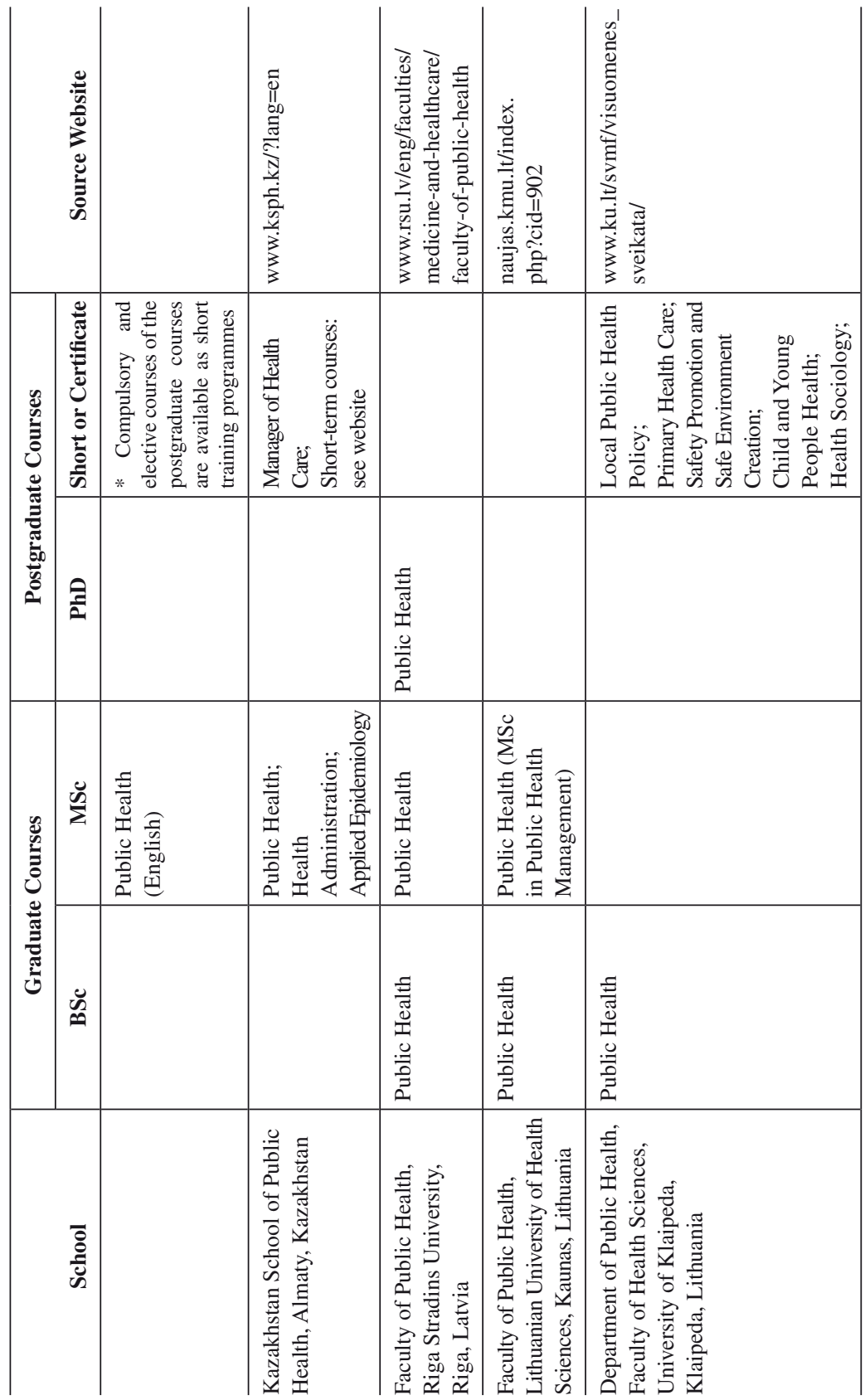




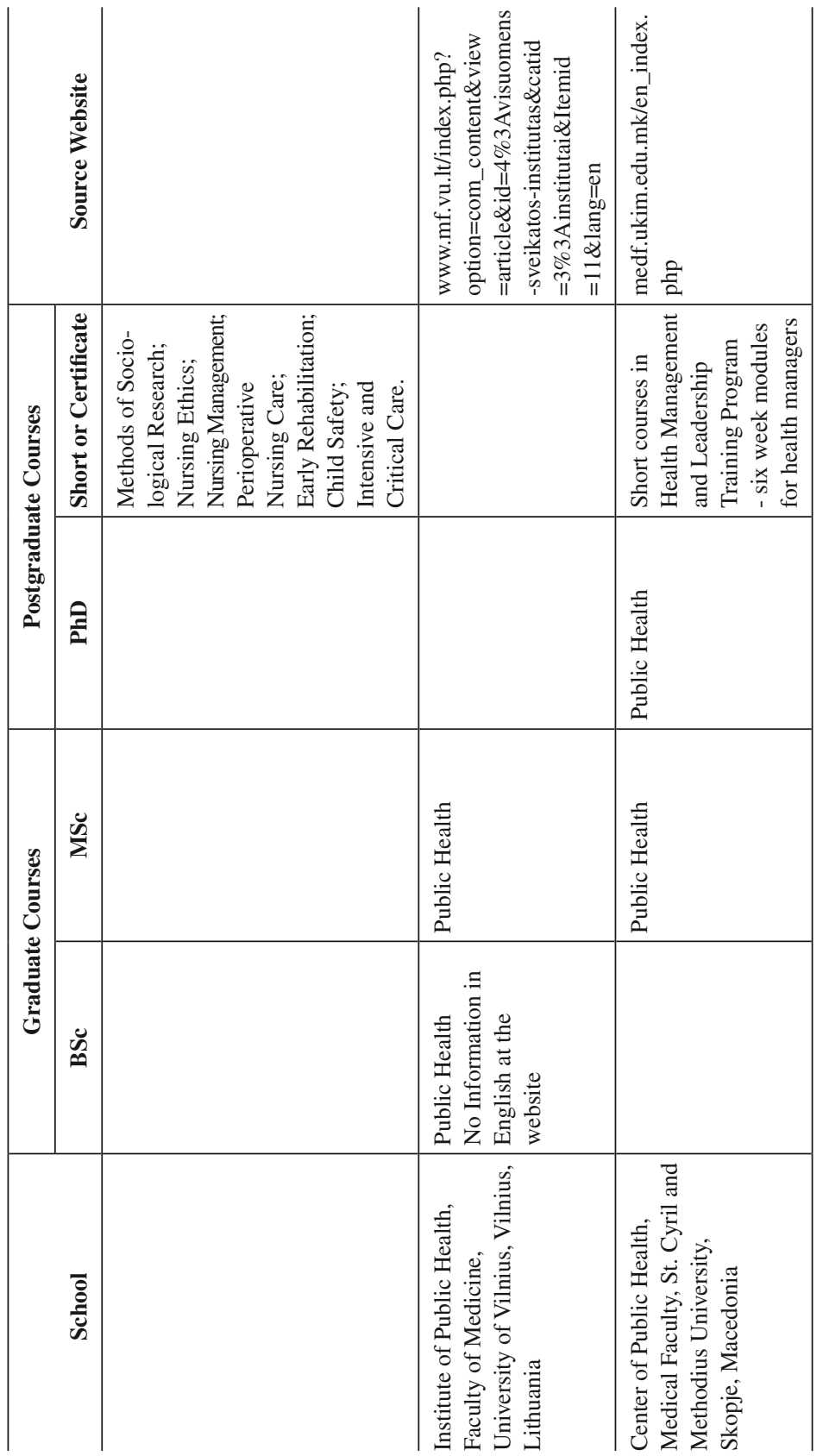




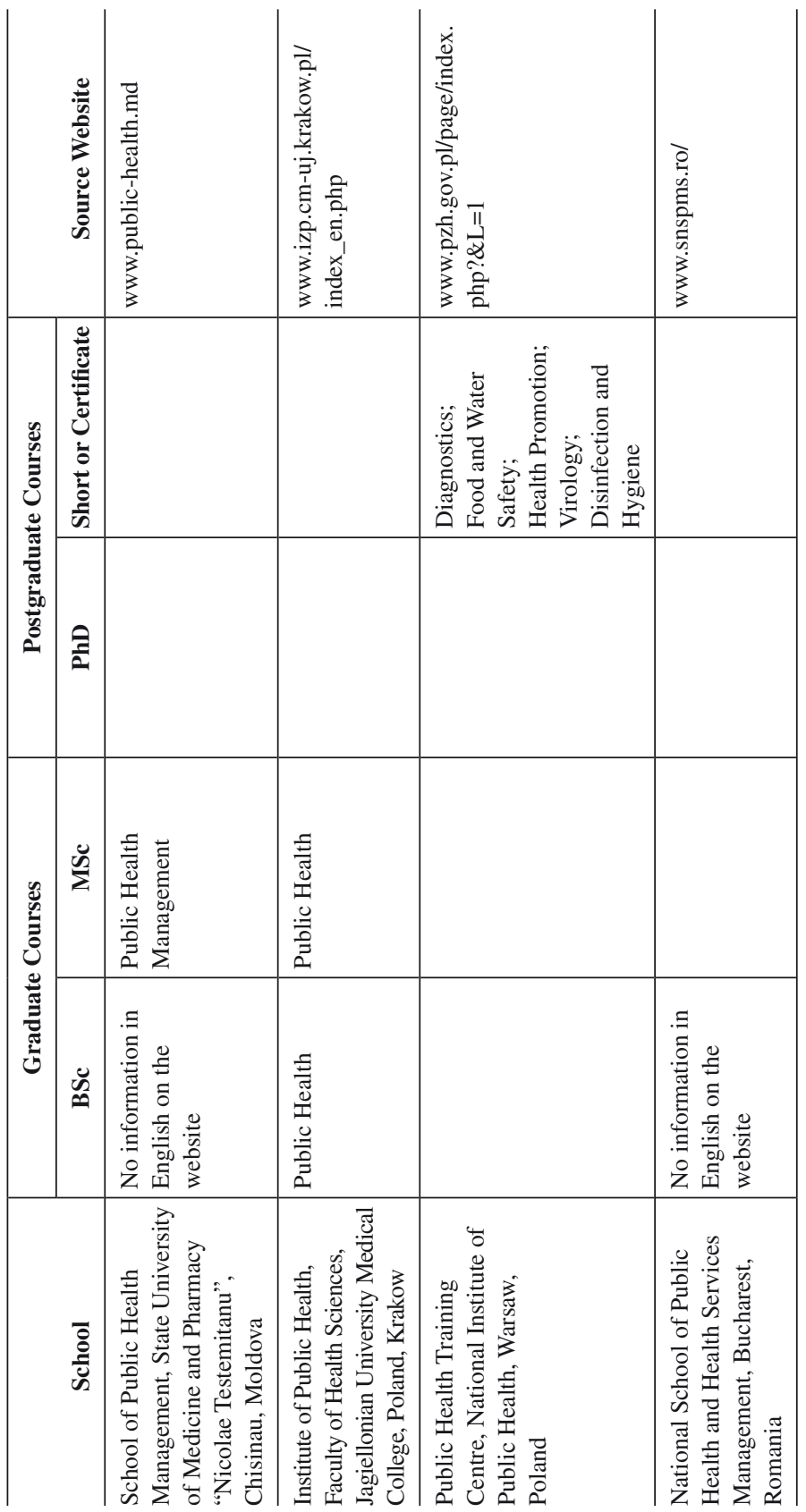




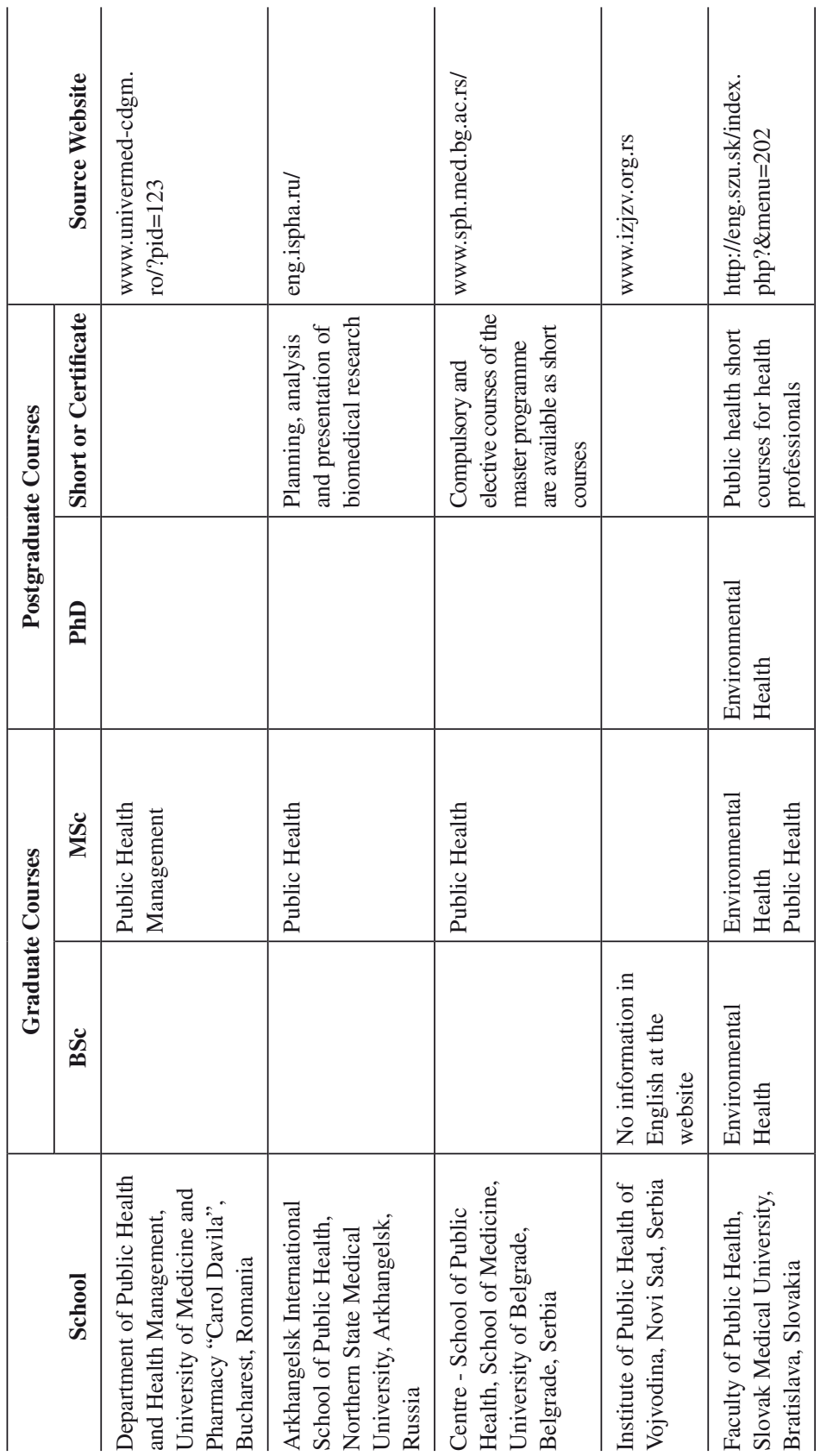




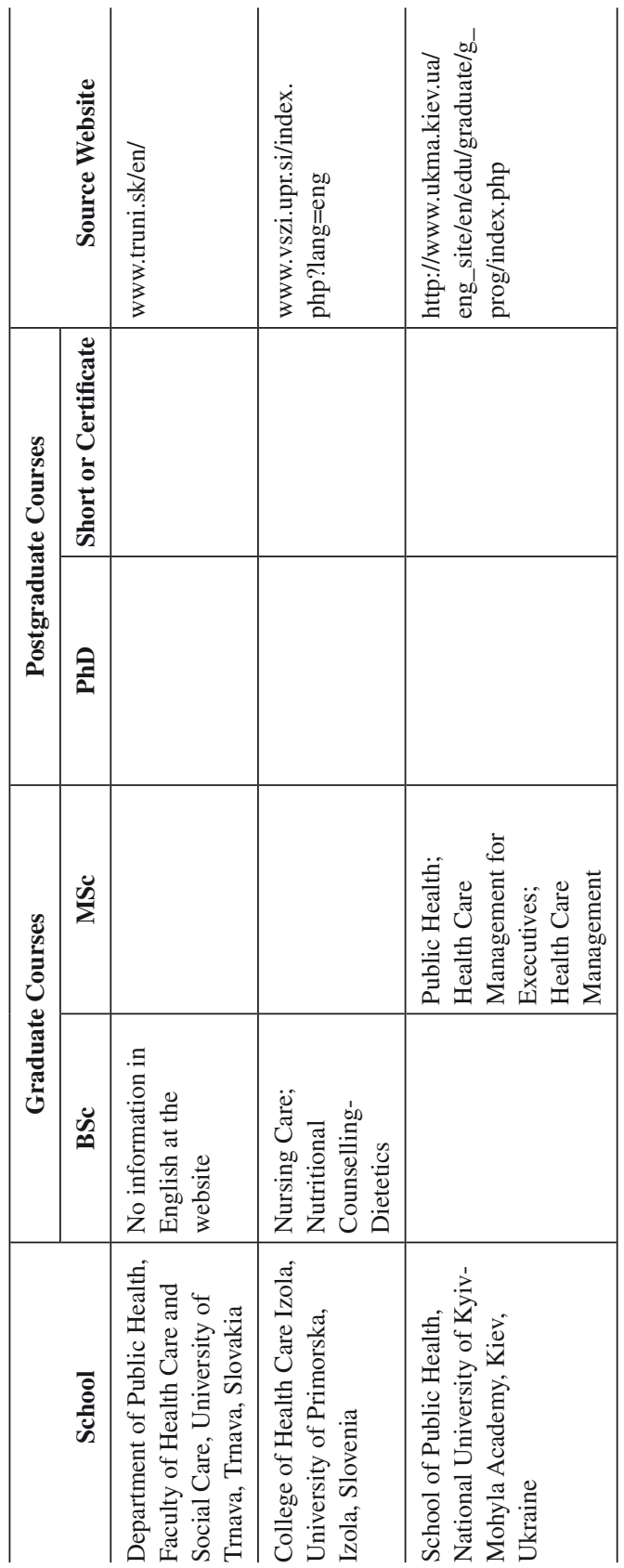




\section{CHARACTERISTICS AND PERSPECTIVES OF SCHOOLS OF PUBLIC HEALTH IN CEE COUNTRIES}

Presently, as listed on their website, ${ }^{32}$ ASPHER includes 27 institutional members (i.e., schools, faculties, departments or units) responsible for education in public health within the CEE region. The training activities for each can be seen in detail on the corresponding school websites (Table 1). Characteristics (e.g., setting, size, teaching profile, etc.) of these institutions vary widely, as well as the type and quality of training provided by them. Some operate by focusing on the traditional hygienic and sanitary control measures, while the newly developed or newly reorganized institutions specify their mission "to promote health and prevent diseases" taking into account the content of the multidisciplinary new public health research and practice. Certain schools operate with only a few staff members and consequently can only cover a narrow field in public health, while a few other institutions provide taught courses for a series of MSc degrees in the field of public health.

Although the public health training network is in a formative phase in the CEE region, there is a common understanding regarding the mission of the schools of public health. The Bologna process facilitated the development of the three-cycle training structure (bachelor's, master's and doctoral), and although today only five schools offer the full spectrum of training and four others offer training at the bachelor's and master's levels (Table 1), the trend indicates the harmonisation of the training structures with the Bologna initiatives. Within the framework of students' and teachers' mobility programmes, exchanges among the schools of public health in the CEE region and other European schools have become very frequent. It is generally accepted that the aim of the schools of the region should be to train specialists who are capable of monitoring public health problems, and planning, implementing and evaluating interventions to solve them. Their main tasks are to equip their students with knowledge and skills for:

- monitoring the health status of the population;

- analysing the factors influencing the health status of populations;

- exploring and prioritising health needs and demands;

- drafting local, regional and national health policy aimed at solving public health problems;

- planning and organising services to promote health, prevent and treat diseases based on the needs of the target population;

- implementing and managing health-promoting and disease-preventing interventions, and finally 
- analysing and evaluating the effectiveness of those services and interventions; and

- increasing the potential for career advancement of their students.

\section{CONCLUSIONS}

The Soviet model of hygiene education and practice differed substantially from those of the Western world. The emphasis on control of infectious diseases and other fundamentals of public health practice did not follow the "epidemiologic transition" in that noncommunicable diseases reached overwhelming dominance in causing morbidity and mortality of the populations of these countries. This now outdated model continues to hold great influence in the former Soviet countries, though the CEE countries had been moderately exposed to western medical and public health ideas even before the collapse of the Soviet Union and the breakup of its constituent republics including those of Yugoslavia.

The activities of ASPHER, OSI and many other bilateral or international funding agencies helped in the process of establishing and reorganizing schools of public health. The new approaches are becoming more understood and accepted among educational authorities responsible for national accreditation in these countries. International cooperation and recognition will be important to the continuation of this process, as will national governmental recognition of just how important this is for improving population health in these regions of Europe.

The introduction of a new public health concept and the fostering of new schools of public health have gradually opened up new vistas in this field which are being manifested by declining mortality rates from many chronic conditions in the CEE. However, the process is slow and even more so in those countries that were part of the Soviet Union itself. The adoption of the new model of public health education and practice has been much slower in the Commonwealth of Independent States (CIS) (i.e., Ukraine, Russia, Belarus) where mortality rates from preventable diseases remain shockingly high.

\section{Acronyms List}

ASPHER = Association of Schools of Public Health in the European Region BRIMHEALTH $=$ The Baltic Rim Partnership for Public Health

CAR $=$ Central Asian Republic

$\mathrm{CEE}=$ Central and Eastern European

$\mathrm{CPH}=$ The Centre of Public Health, Macedonia

$\mathrm{KSPH}=$ The Kazakhstan School of Public Health 
MPH = Master of Public Health

MPHM = Master in Management of Public Health

$\mathrm{MScPH}=$ Master of Science in Public Health

NIS $=$ Newly Independent States

OSI $=$ The Open Society Institute

PEER = Public Health Education European Review

Sanepid $=$ Sanitary Epidemiological

USAID $=$ The United States Agency for International Development

\section{REFERENCES}

1. World Health Organization. European Health For all Database (HFA-DB). Geneva: WHO; 2011. Available from URL: http://www.euro.who.int/en/ what-we-do/data-and-evidence/databases/european-health-for-all-databasehfa-db2 (Accessed 9 September, 2011).

2. McKee M, White M, Bojan F, Osrbye T. Development of public health training in Hungary - an exercise in international co-operation. J Public Health Med. 1995; 17:438-44.

3. Adeyi O, Chellarai G, Goldstein E, Preker A, Ringold D. Health status during the transition in Central and Eastern Europe: development in reverse? Health Policy Plan. 1997;12:132-45.

4. Oreskovic S. New priorities for health sector reform in Central and Eastern Europe. Croat Med J. 1998;39:225-33.

5. Tulchinsky TH, Varavikova EA. Addressing the epidemiologic transition in the former Soviet Union: strategies for health system and public health reform in Russia. Am J Pub Health. 1996;86:313-20.

6. Bury J, Gliber M. Quality Improvement and Accreditation of Training Programmes in Public Health. Fondation Merieux - ASPHER, 2000-2001. Lyon: Edition Fondation Merieux; 2001.

7. Goodman J, Overall J, Tulchinsky T. Public health workforce capacity building. Lessons learned from "quality development of public health teaching programmes in Central and Eastern Europe". Brussels: ASPHER; 2008.

8. The European Master of Public Health. Vademecum. Available from URL: www.aspher.org/pliki/pdf/vademecum.pdf (Accessed 1 August, 2011).

9. Ádány R, Hajdú PV, Széles G, Vokó Z, Kósa K. Public health challenges of the 21 st century and the role of schools of public health in Central and Eastern Europe. Public Health Rev. 2002;30:15-33.

10. Pavlekovic G, Sosic Z, Kenfelj H, Ivankovic D, Dezelic N, Vuletic S. [A comprehensive program in the fight against chronic non-infectious diseases in a basic population group-the Belec Study. IV. The interventional model.] Lijec Vjesn. 1992;114:220-6. [In Croatian].

11. Kaldmae P, Priimagi L, Raudsepp A, Grintchak M, Valjaots E. Promotion of safer sexual behaviour and HIV/STD prevention among adolescent students and army recruits. AIDS Care. 2000;12:783-8. 
12. Egészséges Nemzetért Népegészségügyi Program 2001-2010. Egészségügyi Közlöny. 2001;51:2237-324.

13. Ministry of Health. National public health programme summary. Budapest; MOH: 2006. Available from URL: http://www.eum.hu/english/public-healthprogramme/national-public-health (Accessed 1 August, 2011).

14. Bjegovic V, Zivkovic M, Marinkovic J, Vukovic D, Legetic B. [Administration of the "Healthy School" project.] Srp Arh Celok Lek 1996;124:184-9. [In Serbian]

15. Sadauskiene R. The influence of the BRIMHEALTH Programme to Public Health development in Lithuania. A descriptive qualitative study. Master of Public Health, MPH 2007:9:. Nordic School of Public Health. Available from URL: http://www.nhv.se/upload/dokument/forskning/Publikationer/ MPH/2007/MPH2007-9_R.Sadauskiene.pdf (Accessed 1 August, 2011).

16. Köhler L, Eklund I. BRIMHEALTH. A successful experience in Nordic-Baltic cooperation in public health training. Eur J Public Health 2002;12:152-4.

17. Villerusa A. Public health training in Latvia. Abstract Book. Baltic Public Health Conference 2010 - Accomplishments and Challenges. Tartu; 2010:21.

18. Indermitte E, Lang K. Public health education in Estonia - 10 years experience. Abstract Book. Baltic Public Health Conference 2010 - Accomplishments and Challenges. Tartu; 2010:20.

19. Moore L, Dixon J. Lessons from Lithuania: rethinking public health training. BMJ 1993;306:911-4.

20. Villerusa A, Stars I. Employment of graduates of the faculty of public health in Latvia. Abstract. 29th ASPHER Annual Conference, Valencia, Spain. 2007;19.

21. Department of Public Health. University of Tartu. Available from URL: http:// www.arth.ut.ee/286738 (Accessed 1 August, 2011).

22. Public health education at Kaunus University of Medicine, Lithuania. Available from URL: http://eu.daad.de/imperia/md/content/eu/mocca/presentations/ mocca_lithuania.pdf (Accessed 1 August, 2011).

23. Kalediene R. Resources for development of training in public health and health management in Eastern Europe: the Kaunas experience. Public Health Rev. 2002;30:145-154.

24. Kulzhanov M, Rechel B. Kazakhstan: Health system review. European Observatory on Health Systems and Policies. Health System in Transition. 2007;9:1-158.

25. Journal of Central Asian Health Service Research. Available from URL: http:// journal.ksph.kz/ (Accessed 1 August, 2011).

26. Ministry of Health: Kazakh School of Public Health. Available from URL: http://www.ksph.kz/?dir=main\&sid=68 (Accessed 1 August, 2011).

27. Ministry of Health. Health Strategy of the Republic of Macedonia, 2020. Safe, Efficient and Just Health Care System. Skopje: MOH; 2007.

28. Donev D, Karadzinska-Bislimovska J, Spiroski M. National Public Health Strategy in Macedonia. In: Scîntee SG, Galan A, Editors: Public Health Strategies: A Tool For Regional Development. A Handbook For Teachers, Researchers, Health Professionals And Decision Makers. Lage; 2005:381-408. 
29. Center of Public Health, Medical Faculty, University "St. Cyril and Methodius". Preliminary Evaluation Group Report, Based on Self Assessment Report and Site Visit for Preliminary Evaluation of the Master of Public Health Program. Skopje; 2005.

30. Ádány R. Festive inauguration of the first Hungarian School of Public Health at the University of Debrecen. Orv Hetil. 2007; 148:1043-5.

31. University of Debrecen, Faculty of Public Health. Available from URL: http:// www.nk.unideb.hu/index.php?langid=en (Accessed 1 August, 2011).

32. The Association of Schools of Public Health in the European Region. (ASPHER).Available fromURL: http://www.aspher.org/index.php?site=aspher_ membership (Accessed 1 August, 2011). 